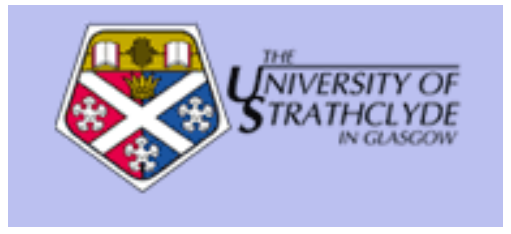

Heron, Gavin (2010) Examing Principles of Formative and Summative Feedback. British Journal of Social Work . ISSN 0045-3102

http://strathprints.strath.ac.uk/20215/

Strathprints is designed to allow users to access the research output of the University of Strathclyde. Copyright (C) and Moral Rights for the papers on this site are retained by the individual authors and/or other copyright owners. You may not engage in further distribution of the material for any profitmaking activities or any commercial gain. You may freely distribute both the url (http://strathprints.strath.ac.uk) and the content of this paper for research or study, educational, or not-for-profit purposes without prior permission or charge. You may freely distribute the url (http://strathprints.strath.ac.uk) of the Strathprints website.

Any correspondence concerning this service should be sent to The Strathprints Administrator: eprints@cis.strath.ac.uk 


\title{
Examining Principles of Formative and Summative Feedback
}

\author{
Gavin Heron*
}

Gavin Heron is a qualified social worker and practice teacher and worked in residential childcare before undertaking his current position as a lecturer. His research interests are social work education and inequality.

*Correspondence to Gavin Heron, Glasgow School of Social Work, University of Strathclyde, 76 Southbrae Drive, Glasgow, G13 1PP, UK. E-mail: gavin.heron@strath.ac.uk

\begin{abstract}
The assessment and feedback practices in social work qualifying courses have to include academic rigour and practice relevance. This study explored the way principles of feedback were evident in the formative and summative feedback given to social work students in relation to a case study that was submitted as part of a portfolio. The findings show that some variation exists in the way principles are evidenced, which suggests some tutors are more able to give feedback in relation to certain aspects of the case study. Differences also existed in the alignment of formative and summative feedback and the extent to which it focused on the tasks specific to the assignment. Establishing first and second order principles could help to conceptualise a more dynamic form of feedback and provide better alignment between formative and summative assignments. This might engage and empower students as more effective learners and provide greater consistency in tutor feedback.
\end{abstract}

Keywords: Feedback principles, formative, summative, case study

\section{Introduction}

Over the past two decades, the social work qualifying course in the UK has moved from Diploma level to an Honours Degree level (three years in England, Wales and Northern Ireland and four years in Scotland). During this period, there has been increasing interest across Higher Education (HE) in developing better engineered assessment and feedback 
processes (Yorke, 2003). Student feedback is an integral aspect of academic life; however, there do not appear to be common frameworks or practices for tutors to adopt. Boud (2000, p. 155) believes that despite the fundamental nature of feedback, it is so 'common place' that it actually gets 'ignored' to the extent that it 'becomes under-conceptualised'. Yet, the importance of feedback in the learning process is well established. For example, in a meta-analysis of over 250 studies, Black and Wiliam (1998) examined a wide range of educational settings and the evidence suggests that significant benefits in learning are accrued from feedback. There is also growing recognition of the importance of formative feedback and how it links with summative feedback. The Quality Assurance Agency for Higher Education (2007) stated that assessment 'of' learning (summative) is limited without corresponding input to assessment 'for' learning (formative). According to Gibbs (2006), an excessive concentration on summative assessment at the expense of formative assessment can lead to students jumping through the assessment hoops and jettisoning efforts to engage in deeper approaches to learning.

The extent to which the HE sector has been willing to address some of the fundamental difficulties in assessment and feedback has been subject to some criticism. For example, Shay (2008, p. 595) argues that 'It has become a fairly common refrain in the educational development literature to acknowledge that there is a crisis in higher education assessment practice'. Perhaps the most recent and powerful signal for change has come from the succession of National Student Surveys in UK that have shown a considerable level of student dissatisfaction with assessment and feedback practices. Such surveys have given greater urgency to the efforts of individual universities, organisations such as the Higher Education Academy and funding bodies across the UK to improve the student experience of feedback and assessment.

Recent strategies to address the deficits in feedback have focused on engaging students more fully in the assessment process. Carless (2007) cites a range of activities, such as the use of exemplars, peer feedback, peer assessment and self-evaluation skills designed to help students use feedback to 'feedforward' into the summative work. O'Donovan et al. (2008) incorporate this type of activity within a 'community of practice' in order to develop a mutual understanding of tacit and explicit knowledge between the student and tutor in the assessment process. The emphasis on student-tutor dialogue and constructivism raises key issues about the balance between formative and summative feedback. For Carless (2007, p. 64), limited resources and risk of creating tutor-dependency when students have engaged in formative activities are reasons to 'speculate' about curtailing summative feedback to 'a few concise points for further development'. Whilst reducing summative feedback to minor points and/ or a grade is controversial, it highlights the need to gain an effective balance between different forms of feedback. 
Recent attempts to provide a more integrated approach to assessment in the UK and across Europe suggest feedback practices may be most effective when student-tutor dialogue is localised. Dahlgren et al. (2009), for example, state that a fundamental difficulty with the European Credit Transfer System (ECTS) is the matching of local knowledge and dialogue with more general criteria that have wider applicability. In order to explore the way in which some of these issues and tensions might mediate upon social work education, this study examined the way principles of feedback were evident in the formative and summative feedback given to students in relation to a case study that was submitted as part of a portfolio.

\section{Principles and self-regulation}

Identifying a set of principles has been viewed as a useful strategy for conceptualising formative and summative feedback (e.g. Sadler, 1989). A key finding in research is the role of feedback in closing the gap between student goals and those of the teachers (Ivanic et al., 2000). The way in which students are empowered to take control of their learning in closing this gap may be influential in shaping their practice. Principles of feedback that are located in the concept of self-regulation (Nicol and MacfalaneDick, 2006; Nicol, 2008) may be of particular relevance to social work because it focuses on empowering students in the assessment process by giving them greater responsibility and control over their learning. Being proactive, questioning and able to self-evaluate personal learning is not simply an academic exercise: such attributes would seem highly relevant to social work practice and life-long learning. Re-balancing power between tutors and students in the assessment process is, however, less than straightforward, as power is not shared equally among social work professionals. For example, in terms of 'race' issues, Williams and Soydan (2005) found social workers in Europe had a 'colour blind' approach to ethnicity and Razack and Badwall (2006, p. 665) believe social workers of colour remain on the margins of North American society. The role of assessment in steering the learning that shapes social work practice is not, therefore, value-free or immune to wider inequalities. Evidence of principles within the feedback might give an indication of its quality and how some of the inherent tensions and complexities of social work practice are conveyed to students.

\section{Portfolio, assessment and practice}

Within social work education, a variety of assessment tools are used to determine students' academic ability and suitability for professional practice (e.g. essay, presentation, report, journal, portfolio, exam and viva). Despite the widespread use of assessment tools, Crisp and Green 
Lister (2002, p. 267) conclude that the evidence to support their effectiveness in social work education is often 'scant or nonexistent'. The portfolio has been adopted as an assessment tool in a range of professional disciplines (Sidell, 2003) and used in social work at pre-qualifying and post-qualifying levels (Slater, 2007). It was selected as the assessment tool in this study for three main reasons. First, it is the assessment tool used for the practice placement and would provide an insight into the way tutors feed back on academic and practice issues. Second, it is considered a 'high-stakes' assignment, as its credit weighting is three times that of classroom-based assignments. Third, unlike most other assessments used on the course, the portfolio incorporates formative as well as summative feedback. Whilst there is no consensus about what constitutes a good portfolio, Doel and Shardlow (1995) emphasise the need for a dynamic interaction between knowledge, value and skills in the learning process.

Portfolios generally consist of a range of materials collected over time that demonstrate achievement and preparedness for practice (e.g. Williams, 2001; Gathercoal et al., 2002). The key features identified in the literature suggest the portfolio offers potential to:

- explore the context of learning;

- provide greater diversity in organising the placement;

- offer a dynamic account of the learning process and practice;

- enable self-assessment, reflection, critical thinking and feedback.

There is less consensus about the way in which assessment and feedback are incorporated within the portfolio. Brew (1995) believes the portfolio is designed for formative and summative assessment and feedback. In contrast, Boud (1995) argues it is a tool that should remain a record of evidence that only the student should read, although evidence might be extrapolated for assessment purposes. The emphasis on external assessment appears to have influenced the recent development of portfolios in social work education. According to Taylor et al. (1999, pp. 148-9), 'portfolios have moved from focussing on the formative to including the summative, from processes to outcomes, and from the private to the public arena' and despite 'its widespread use, there is surprisingly little critical analysis of its application in social work'. For these authors, the individualised nature of an assessment, which often takes several months to compile, represents conditions that can 'defy standardisation'. Additional problems can occur when portfolios become too complicated and unwieldy in terms of guidance and content (Edwards and Kinsey, 1999). This has resulted in concerns over the reliability of feedback between markers and the need for greater exploration of portfolios in social work education (Risler, 1999). 


\section{Study design}

This study explored the way principles of feedback were evident in the formative and summative feedback given to social work students in relation to a case study that formed a major part of the portfolio. The materials included in the portfolio at the interim and final stage comprised the following parts:

\section{Interim stage}

Practice learning contract

Pen picture

\section{Self-assessment}

Appraisal of the context of the placement (1,000 words)

A summary of work

Student record of evidence

Review of learning (1,000 words)

A plan for the case study (500 words)

Documentary evidenced including: practice teachers' midpoint feedback, one critical incident analysis (1,000 words), one direct observation, three extracts from the learning log, service user/carer feedback and a reference list.

\section{Final stage}

Tutor feedback on midpoint submission

Case study (3,000 words)

Final review of learning (1,500 words)

Documentary evidence including: practice teacher's comments and assessment, two further direct observations, two further critical incidence analyses, three additional extracts from learning logs, tutor feedback on midpoint submission, service user/carer feedback and a reference list.

Whilst several parts of the portfolio incorporated formative or summative feedback, the case study and review of learning were the only parts that were assessed formatively at the interim stage and summatively at the final stage of the placement. It would have been possible to use both of these assignments, given the nature of this study. However, it was decided to focus on the case study for two main reasons. First, the case study is the largest single piece of work ( 500 words at the formative stage and 3,000 words at the summative stage) within the portfolio. Second, being 'a critical explanation and evaluation of an example of 
your own practice undertaken as part of your assessed practice learning in the agency' (Glasgow School of Social Work, 2007, p. 34), the case study is the main part of the portfolio, where students integrate theory and direct practice.

The portfolios examined for this study were from year two students on an undergraduate four-year social work qualifying course in Scotland. Students undertake a practice placement in years two and four with a portfolio linked to each placement. Formative feedback was given by the student's tutor and the summative feedback was given by a different tutor. The rationale was to give students an opportunity to have dialogue with their tutor at the formative stage whilst ensuring anonymity of marking at the summative stage. The case study, as with all sections of the portfolio, had to adhere to the standard conventions for submitting assignments (e.g. inclusion of suitable references). Thirty-three students were present when the request was made to participate in the study and thirty students gave consent for their portfolio to be used. No enquiries were made of the three students who declined to participate. The departmental ethics committee sanctioned the study.

Twenty-six of the thirty participants were female and no students were from black or minority ethnic groups. Four students who gave consent were not included because the portfolios were incomplete or missing from the archive. This provided fifty-two case studies (twenty-six formative and twenty-six summative) and fifty-two feedback sheets (twenty-six formative and twenty-six summative) from which to examine evidence of principles of feedback. Any comments by tutors that might have been written on the script were not available, as the study used archive copies, with the originals being returned to students. The feedback examined for this study was therefore partial, as relevant information may have been written on the scripts. Accessing original scripts would have provided a more complete account; however, it seems plausible to assume that the most important information was provided on the feedback sheets.

\section{Coding principles and tasks}

Nicol (2008) provides twelve principles of feedback designed to enhance assessment practices. Seven of these principles were used to examine the feedback given to students. The remaining five principles focused on the design and construction of teaching and assessment practices and would not be evident in tutor feedback. For example, Principle 12 focuses on the need to 'Provide information to teachers that can be used to help shape the teaching'. This principle informs tutors' thinking about how such feedback might enhance future teaching; however, it would not be explicit in any feedback. The seven principles that could be expected to be present in feedback were: 
1 Help clarify what good performance is (goals, criteria, standards).

2 Encourage time and effort on challenging learning tasks.

3 Deliver high-quality feedback information that helps learners self-correct.

4 Provide opportunities to act on feedback (to close any gap between current and desired performance).

5 Encourage interaction and dialogue around learning (peer and teacherstudent).

6 Facilitate the development of self-assessment and reflection in learning.

7 Encourage positive motivational beliefs and self-esteem.

The guidance for the case study stipulated five tasks that students were to undertake. These tasks contributed to the learning outcomes for the portfolio and were as follows:

1 Set the context for practice including responsibilities.

2 Provide a critical analysis of work and the learning gained.

3 Refer to specific theories, literature and knowledge underpinning practice.

4 Explain professional values including how conflicts were resolved.

5 Give an account of their own contribution to practice.

Students were assessed on the extent to which they evidenced these tasks within the case study. Principles of feedback were examined in relation to each of these tasks. When coding the feedback, it became apparent that a number of principles related to more 'general' tasks. In order to include this information in the analysis, four additional tasks (giving a total of nine) were created:

6 Referencing.

7 Learning outcomes.

8 Presentation/structure.

9 Miscellaneous (e.g. comments about practice teacher's feedback).

Examining evidence of seven principles across nine tasks gave sixty-three permutations for coding in each of the formative and summative feedback sheets produced by tutors.

Identifying a principle that applied to one of the nine tasks was often less than straightforward. Feedback did not always fit neatly with a particular principle and could apply to more than one task. For example, it was sometimes difficult to differentiate between Principle 3 (self-correct) and Principle 4 (close the gap), as the tutor comments might apply to both principles (helping students to 'self correct' the feedback might also 'close the gap'). The following extract from a tutor's formative feedback illustrates this point: 
Some of the time you mention theory, you don't demonstrate any understanding of or ability to apply it at all (this doesn't mean you don't understand and can't apply, just that you didn't demonstrate).

This feedback clarifies the gap and, in doing so, implies what the student has to do. This was coded as Principle 4 in relation to Task 3 because there was a greater emphasis on closing the gap than self-correction. When such overlap occurred, the principle that was considered most evident in the feedback was used. Another difficulty in coding arose from feedback that was not linked to any particular part of the portfolio. Feedback that might be applicable to the case study, even although it was not explicitly linked to it by the tutor, was also coded. This clearly involved a subjective judgement when applying a set of principles to a practical study.

\section{Results}

Within the fifty-two feedback sheets there were 1,094 instances (596 formative and 498 summative) in which principles were evident in the feedback. Figure 1 shows the frequency of these principles in relation to the different tasks for the case study.

There was some variation in the way principles were evident in each of the tasks. The majority of principles were linked to Task 3 , which required students to 'refer to specific theories, literature and knowledge underpinning practice'. The formative feedback also had more evidence of principles, albeit rather minimally in some instances, in seven of the nine tasks compared to summative feedback. Tasks $1-5$ will be examined in detail, as these were specific to the case study.

\section{Context of placement}

Task 1 requires students to 'set the context for practice including responsibilities'. In relation to this task, there was evidence of fifty-three principles

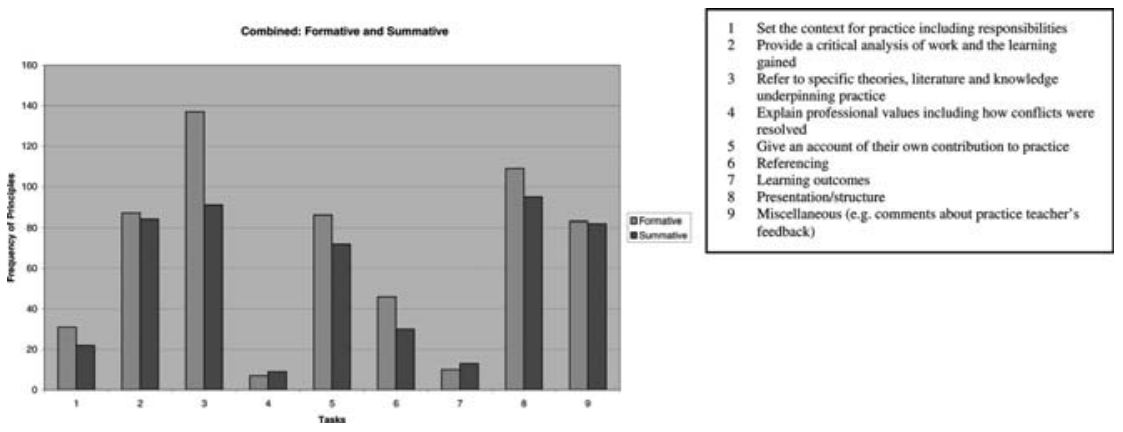

Figure 1 Frequency of principles for each of the tasks 
being applied in thirty-one instances of formative feedback and twenty-two instances of summative feedback. Eighteen students received formative feedback and fifteen students received summative feedback on this task. Only ten students received formative and summative feedback in relation to this task. In the following extract, formative feedback by the tutor provides clarification (Principle 1) about the nature of the placement:

This portfolio provides a lively, credible and authentic record of the student's work in an unusual placement setting where social work in a traditional sense is never the purpose.

The placement context is clearly important for student learning and there was an expectation that more students would have received both formative and summative feedback. A possible explanation is that tutors do not give feedback on the learning context because they do not fully recognise its importance or lack sufficient knowledge about the placement setting. Tutors in this study had as many as ten students on placement and may have had insufficient time to develop a detailed understanding of placements. Consequently, they may not have felt suitably equipped to give detailed feedback about the placement context.

\section{Critical analysis}

Task 2 requires students to "provide a critical analysis of work and the learning gained'. In relation to this task, there was evidence of 171 principles being applied in eighty-seven instances of formative feedback and eightyfour instances of summative feedback. Twenty-five students received formative feedback and twenty-four students received summative feedback for this task. Twenty-three students received formative and summative feedback in relation to this task. The following extract from summative feedback encourages the student to self-correct (Principle 3) in relation to anti-discriminatory practice:

In anti-discriminatory practice your submission would have been strengthened by an additional piece of work reflecting on the accessibility of the agency to the ethnic minority population in the catchment area.

Tutors were usually quite specific about those areas requiring greater levels of critical analysis. Such feedback was most frequently linked to overly descriptive writing or a failure to link certain ideas and concepts to relevant literature. The high number of students receiving both formative and summative feedback about critical analysis would suggest it is an area in which tutors are able and/or willing to comment upon with consistency.

\section{Theories, literature and knowledge}

Task 3 requires reference 'to specific theories, literature and knowledge underpinning practice'. In relation to this task, there was evidence of 228 
principles being applied in 137 instances of formative feedback and ninety-one instances of summative feedback.

Twenty-four students received formative feedback and twenty-two students received summative feedback for this task. Twenty students received formative and summative feedback in relation to this task. The most common aspect was the need for greater levels of integration of theory and practice, especially at the formative stage. In the following extract, the tutor attempts to assist the student in closing the gap between current and desired performance (Principle 4):

... more integration of theory and practice especially in relation to assessment and communication skills.

The high frequency of principles evident in relation to this task suggests it is an area that tutors prioritise and/or feel particularly able to comment upon.

\section{Values}

Task 4 requires students to 'explain professional values including how conflicts were resolved'. In relation to this task, there was evidence of sixteen principles being applied in seven instances of formative feedback and nine instances of summative feedback. Only one student received formative and summative feedback in relation to this task. Feedback was usually quite brief and tended to highlight the need for value issues to be developed or expanded. An extract from formative feedback (Principle 1) illustrates this point:

It is important you expand on the role of your professional values in relation to your practice.

Despite this feedback, the student made no reference to values in the summative assignment. Irrespective of whether the student ignored or was unable to implement the formative feedback in this respect, the summative feedback did not include any comment about values. Only one student was given feedback specific to resolution of conflict:

How were value issues addressed and how did this influence the way you dealt with conflict?

There was no specific mention of actual values (e.g. right to selfdetermination, respect for the individual) in the feedback. It is not clear why value issues do not feature to any extent in the feedback. Perhaps staff did not recognise the absence of values in assignments or found it more difficult to comment compared to the other tasks. Given the importance of values for professional development, it is difficult to foresee how students might develop an understanding of complex and controversial areas of practice such as anti-discrimination and anti-racism when values are marginalised in feedback. A more rigorous approach to communicating 
values in feedback might be needed in order to reflect the importance of this aspect within social work practice.

\section{Student contributions}

Task 5 requires students to 'give an account of their own contribution to practice'. In relation to this task, there was evidence of 158 principles being applied in eighty-six instances of formative feedback and seventy-two instances of summative feedback. Twenty-three students received formative feedback and twenty-three students received summative feedback in relation to this task. Twenty students received formative and summative feedback. An extract from the formative feedback encourages the student to self-correct (Principle 3) in relation to communication skills:

The range of communication skills you use in the assessment process should be supported by theory.

Tutors focused on a range of areas (e.g. relationships with clients) with regards to students' practice but they rarely encouraged interaction and dialogue in relation to the student's contribution to practice. If students are not encouraged to discuss their contribution to direct practice, it is difficult to know how tutors are gaining an insight into the placement as a learning context.

The variation in frequency of principles across the five tasks highlights some of the complexities in aligning formative and summative feedback. The different frequency of principles in the feedback suggests tutors gave greater consideration to certain tasks. This was not made explicit to students and the imbalance might have been quite unintentional.

Providing feedback to some students and not others on certain tasks seems unfair in terms of assessment for learning. If students are required to perform specific tasks as part of an assignment, a baseline for tutors is to provide both formative and summative feedback on each of these tasks, otherwise learning may suffer because tutors are sending mixed messages about those aspects deemed to be most important. Engaging students in formative activities designed to feed forward into summative assignments (e.g. Carless, 2007) may have limited impact if not preceded by tutor activities designed to ensure the marking team is capable of achieving greater consistency and alignment between formative and summative feedback.

\section{Static and dynamic feedback}

Figure 2 shows the frequency of each of the seven principles in the formative and summative feedback. The frequency of evidence for the seven principles shows considerable variation in the way they were evident in tutor feedback. The variation was particularly apparent for Principle 1 (help 


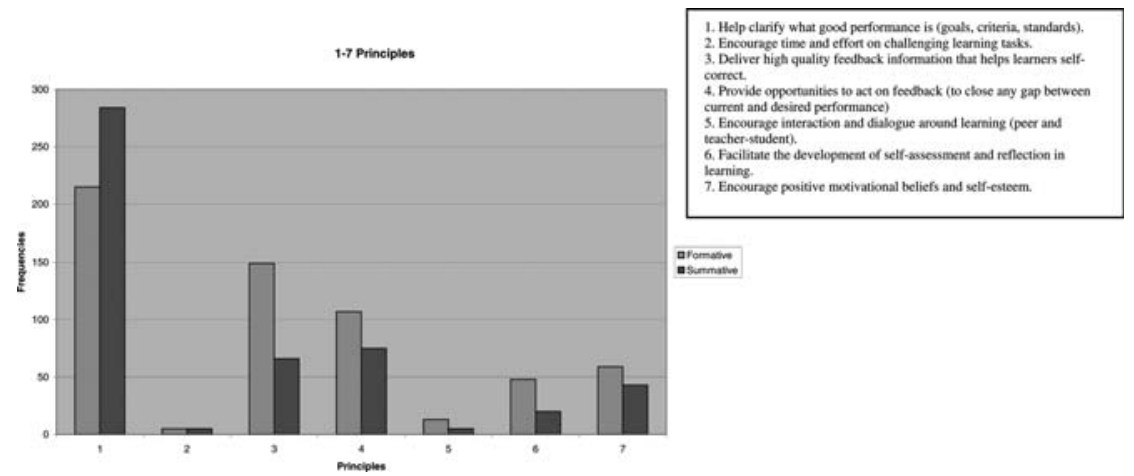

Figure 2 Frequency of principles in formative and summative feedback

clarify what good performance is) in the summative feedback. The frequency of this principle was greater than the total number of principles evident in the rest of the feedback. This variation suggests that some principles, as with the tasks, were given greater emphasis by tutors. Again, the extent to which this might be intentional or desirable was unclear.

Clarifying good performance is clearly a crucial aspect of feedback and it is reassuring that it was evident in formative and summative feedback to such an extent. However, the lower frequency of some other principles indicates an imbalance in the instruction given to students. Clarification may be crucial to enhancing students' understanding, but on its own, it may be somewhat 'static'. Clarification focuses on what the student has done and does little to move the student's learning forward. Without linkage to other instructions, it may be inadequate to close the gap between the goals of the student and those of the tutor. Creating a more dynamic form of feedback may be located in the principle that was least evident in the feedback, 'encourage time and effort on challenging learning tasks'. This principle reflects the activity the student has to do in order to close the gap. The following extract from a student's formative feedback comments upon her practice:

\footnotetext{
... it might be useful to examine why a café was used for a meeting with an unaccompanied asylum seeking child and link this to the placement context (e.g. confidentiality, resources and some statistics on age, gender, ethnicity etc).
}

This instruction gives a challenging task in that it enables the student to make greater connections between her practice and those specific factors that might limit the quality of service provided to a client. Instruction that helps the student to close the gap may be conducive to a more dynamic form of feedback. This might be enhanced by greater studenttutor interaction. The low frequency of Principle 5 (encourage interaction 
and dialogue around learning) suggests tutor-student dialogue was seldom explicitly encouraged in feedback. Greater levels of interaction that focused on achieving challenging learning tasks might be a useful way of creating a more dynamic form of feedback.

\section{Dilution of feedback}

Achieving greater levels of consistency between formative and summative feedback may be undermined by the inclusion of more 'general' instruction. Evidence of principles unrelated to the specified tasks for the case study suggests students might be exposed to more general feedback that could be considered less of a priority. Table 1 shows the comparison between the number of principles in relation the five specific tasks and the four general tasks that were added for the purpose of this study.

The inclusion of feedback on these general tasks may risk diluting the specific feedback for the case study. Although the four general tasks were not listed in the guidance for the case study, normal academic conventions applied to the portfolio in terms of aspects such as presentation/structure and referencing. Differentiating more clearly between specific and general feedback may assist tutors when focusing on the priorities for a particular assignment. If classroom-based assignments require adherence to criteria such as referencing and presentation/structure, it might be more effective to limit feedback on these aspects in the case study/portfolio. For example, feedback on the former could be limited to a tick-box approach because detailed comments on such matters can be given in other assignments. Doing so would save time and ensure the narrative focused solely on the tasks specific to the case study. A particular difficulty with this approach is that general feedback may have a different meaning for practice-based assignments compared to classroom-based assignments, and excluding it or demoting it to a tick-box exercise could risk undermining its relevance. Perhaps the key point is that tutors should refrain from trying to give feedback on 'everything'. Consistency might be more achievable when tutor-student dialogue prioritises the tasks that are to be given feedback.

Greater consistency might also be achieved by incorporating formative feedback in a wider range of assignments. The portfolio is one of the few assignments on the four-year course to use formative feedback, which means there is little opportunity to practise, either in terms of staff

Table 1 Number of principles in relation to specific and general tasks

\begin{tabular}{lll}
\hline Case study & Tasks (specific) $1-5$ & Tasks (general) 6-9 \\
\hline Formative principles & 348 & 248 \\
Summative principles & 278 & 220 \\
\hline
\end{tabular}


delivering the formative feedback or for students to interpret and act upon it. The irony is that inconsistency was generated in a major assignment by tutors when the stakes for students were highest. Incorporating formative feedback in classroom-based assignments would give tutors and students more opportunity to practise before a major practice-based assignment is expected. Having the same tutor provide formative and summative feedback for each assignment might also provide better alignment by (i) limiting the inconsistencies that might arise between two different tutors; and (ii) reducing some of the misconceptions and anxieties that students might have when trying to second-guess how another tutor wants them to act on the formative feedback. Although anonymity would be lost when marking the summative assessment, it might be worth it if greater levels of consistency were achieved.

\section{Repetition and volume}

Addressing the imbalance of feedback in relation to tasks and the principles might be helped by reducing some of the repetition. This was particularly evident for 'presentation/structure' (Task 8) and occurred most often in relation to Principle 1 (help clarify what good performance is). For example, one student received summative feedback evidencing ten principles in relation to presentation. Does such repetition equate with good learning? Not only is such repetition time-consuming for the tutor, but it may be confusing for the student to receive information that is overly similar. Reducing the frequency of such repetition would save time and if augmented by comments that incorporated other principles, especially those that were relatively infrequent, might help to produce higher-quality feedback.

On average, it would appear that students receive more feedback on the formative case study (491 words) than the summative (391 words) (Table 2). The level of feedback suggested a rigorous approach to delivering formative feedback. Whilst this was reassuring, it might be disproportionate given the formative case study was 500 words whereas the summative case study was 3,000 words. This imbalance was also reflected in the

Table 2 The maximum, minimum and mean number of principles and words in feedback sheets

\begin{tabular}{llcc}
\hline & & Principles & Word count \\
\hline Formative & Maximum & 39 & 1,022 \\
& Minimum & 10 & 154 \\
Summative & Mean & 23 & 491 \\
& Maximum & 35 & 784 \\
& Minimum & 9 & 176 \\
& Mean & 19 & 391 \\
\hline
\end{tabular}


principles. The mean number of principles in formative feedback was twenty-three compared to nineteen in the summative feedback. There was a clear link between the word count, number of principles and repetition. Feedback sheets with high word counts evidenced more principles and usually incorporated more repetition. Conversely, feedback sheets with low word counts evidenced fewer principles and less repetition. Deciding on the most appropriate word count or frequency of principles that might be most effective in student learning is complex and likely to be determined by a range of factors (e.g. type of assignment, individual learning needs and tutor workload). A pertinent issue for tutors is to justify the differences in feedback within the student cohort. Might feedback of 1,022 words and thirty-nine principles of feedback for a 500-word formative case study represent spoon-feeding, irrespective of its quality and good intent? Could the same instruction be given with 154 words and ten principles of feedback? There is no suggestion that length of feedback equates with quality; however, the differences in some feedback does question the level of consistency across the staff team.

\section{Discussion}

Findings from this study showed variation in the way principles of feedback were evident in a case study that formed a major part of a portfolio. This would suggest that tutors were more able to give feedback in relation to certain tasks and evidence some principles more than others. Differences also existed in the alignment of formative and summative feedback for tasks in the case study. For three of the five tasks in the case study, twenty to twenty-three students received both formative and summative feedback. Ten students received formative and summative feedback in relation to one of the tasks and only one student received both forms of feedback for one task. The high frequency of principles in formative feedback suggests that it was viewed by tutors in this study as an important feature of the assessment. This is reassuring given concerns by The Quality Assurance Agency for Higher Education (2007) that formative feedback is undervalued by academics. The volume of formative feedback might, however, be disproportionate given it was based on a 500-word case study and several tasks had more feedback at the formative than summative stage. Reducing the variation and imbalance between formative and summative feedback may provide more focused instruction for students and enhance consistency across the staff team.

If the variation between tasks and principles was replicated across each part of the portfolio (e.g. case study, review of learning, direct observations, critical incident analyses), concerns by Taylor et al. (1999, p. 149) that portfolios can 'defy standardisation' may have some validity in terms of student feedback. Portfolios with too many parts could reflect a scattergun 
approach in which there is a desire to assess 'everything'. When experienced practitioners find it difficult not to 'throw in everything but the kitchen sink' into the portfolio (Slater, 2007, p. 756), too much material may create the conditions for ineffective and/or overly complicated feedback for undergraduates. Reducing the variation in feedback could be achieved by prioritising the tasks that are most pertinent to the assignment. A considerable amount of feedback in this study was 'general' in that it might be equally applicable to classroom-based assignments. There may be a risk that specific tasks in the case study become diluted or marginalised by feedback on these more general tasks (e.g. presentation/structure). This might serve to undermine the uniqueness of the portfolio as a practicebased assignment.

\section{First and second order principles}

Re-conceptualisation feedback in a more dynamic way could be achieved by organising the seven principles used in this study into first and second order principles (Figure 3). First order principles would be defined by a collective potential to create a more dynamic form of feedback. Connecting the three first order principles could move the feedback from 'clarification' (Principle 1) by providing a 'challenging task' (Principle 2) in order to 'close the gap' (Principle 4). These first order principles would be evident in all of the tasks in the case study. The presence of second order principles that 'self correct' (Principle 3), 'encourage interaction' (Principle 5), 'develop selfassessment and reflection' (Principle 6) and 'encourage motivation' (Principle 7) are optional and could be selected individually or in a combination that enhanced the meaning of the first order principles. This feedback would represent a 'thread' that linked each of the formative and summative tasks within the feedback (Table 3).

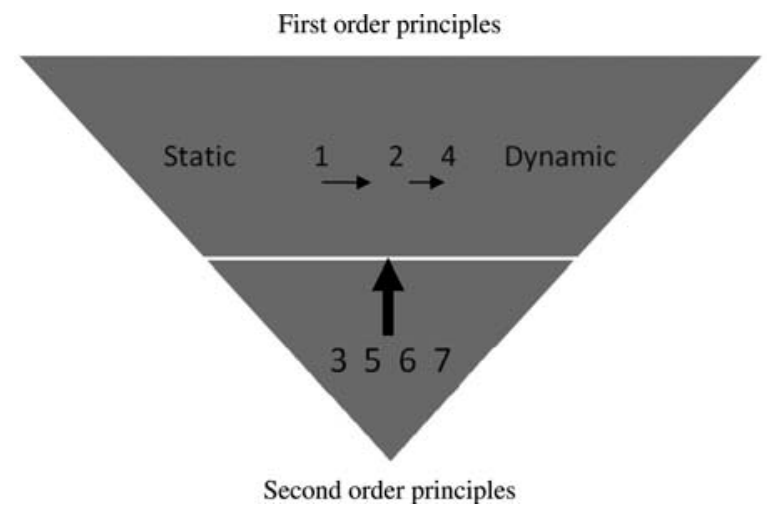

Figure 3 First and second order principles 


\begin{tabular}{lll}
\hline & Feedback threads & \\
\cline { 2 - 3 } Tasks & Formative & Summative \\
\hline 1 & & \\
2 & & \\
3 & & \\
4 & & \\
5 & & \\
\hline
\end{tabular}

When linked to first and second order principles, the feedback sheet would have scope to provide clearer information about what students might expect to receive in terms of feedback and what tutors are expected to provide. The alignment between formative and summative feedback would also be made more explicit. Including the formative feedback in the final submission would allow the summative feedback to build upon existing work in a cumulative way, rather than simply providing a second 'snapshot' of the assignment. Using first and second order principles could enhance consistency among staff because it provides greater focus for tutor-student dialogue. Tutors need to be explicit about the precise nature of the feedback they can provide in terms of accuracy and validity. Perhaps this should be the starting point when devising learning outcomes for classroom-based teaching and practice placements: unless tutors can feed back with consistency, it is likely to have a detrimental effect on student learning.

A mutual understanding of first order principles - 'clarification', 'challenging tasks' and 'closing the gap'-could be developed in the communities of practice proposed by O'Donovan et al. (2008) using assessment activities (e.g. peer review, use of exemplars) in order to enhance the way feedback is delivered and received. The extent to which dialogue within any one community of practice might have wider applicability is, however, questionable. Principles of feedback might be sufficiently abstract to have 'wider' meaning; however, their application may be more 'unique' because the interpretation derived from the tutor-student dialogue is grounded within the local knowledge in a particular community. Future research might explore a range of different communities within $\mathrm{HE}$ in the UK and internationally in order to considerer the feasibility of integrating different feedback practices.

Using a feedback grid with tasks and first order principles as presented in this study may appear over-simplified; however, O'Donovan et al. (2000) warn of complicated grid formats and the futility of producing numerous assessment criteria. Instruction on all of the formative and summative parts of the portfolio may result in feedback overload where priorities in student learning get confused by the very mechanism that is intended to 
enhance it. This may reflect Risler's (1999) concerns about the reliability of feedback when using portfolios. The potential for overload and confusion might be greater for practice-based assignments because they usually incorporate feedback from tutors and practice teachers. Heron (2008) noted excessive feedback for some students and a variety of inconsistencies between practice teachers and tutors. When tutors and practice teachers, many of whom have considerable experience as social work practitioners, have difficulty providing consistent and aligned feedback, it begs the question of how students learn to give and receive feedback on practice issues, especially when these are often significantly more complex than a paperbased academic assignment. The developing theoretical and empirical base around assessment is forcing academia to ask fundamental questions about past, current and future practice. Social workers may have to ask similar questions about the feedback exchanged between service users, colleagues, managers and the range of other professions involved in interagency assessments.

\section{Conclusion}

Findings in this study suggest there were inconsistencies and a lack of alignment in the formative and summative feedback provided by tutors in relation to a case study that formed a major part of a portfolio. Such discrepancies are not conducive to effective learning and raise issues of equity in terms of the way feedback is provided to students. Differentiating between first and second order principles could provide greater focus for studenttutor dialogue. Principles of feedback may also offer a useful conceptual framework to explore greater integration across HE in the UK and internationally; however, the implementation of such principles within communities of practice may create local knowledge that lacks wider applicability. For any dialogue to be meaningful, power will have to be rebalanced between students and tutors in the assessment process. This would require tutors to refrain from trying to assess 'everything' and be more specific about what they can feed back with accuracy and validity. Having identified some of the difficulties tutors encounter when giving feedback on a placement-based assignment for year two students, it may be appropriate to ask how effective social work practitioners are in giving and receiving feedback in the workplace. After all, the realities of practice are likely to be much more complex than a paper-based assignment.

\section{References}

Black, P. and Wiliam, D. (1998) 'Assessment and classroom learning', Assessment in Education, 5(1), pp. 7-74. 
Boud, D. (1995) Enhancing Learning through Self Assessment, London, Kogan Page.

Boud, D. (2000) 'Sustainable assessment: Rethinking assessment for the learning society', Studies in Continuing Education, 22(2), pp. 151-67.

Brew, A. (1995) 'Self assessment in different domains', in Boud, D. (ed.), Enhancing Learning through Self Assessment, London, Kogan Page.

Carless, D. (2007) 'Learning-orientated assessment: Conceptual bases and practical implications', Innovations in Education and Teaching International, 44(1), pp. 57-66.

Crisp, B. R. and Green Lister, P. (2002) 'Assessment methods in social work education: A review of the literature', Social Work Education, 21(2), pp. 259-69.

Dahlgren, L. O., Fejes, A., Abrandt-Dahlgren, M. and Trowald, N. (2009) 'Grading systems, features of assessment and student approaches to learning', Teaching in Higher Education, 14(2), pp. 185-94.

Doel, M. and Shardlow, S. (1995) Preparing Post Qualifying Portfolios: A Practical Guide for Candidates, London, Central Council for Education and Training in Social Work.

Edwards, K. and Kinsey, E. (1999) 'The place of NVQ 4 in the training continuum', Social Work Education, 18, pp. 271-85.

Gathercoal, P., Love, D., Bryde, B. and McKean, G. (2002) 'On implementing web-based electronic portfolios', Educause Quarterly, 25, pp. 29-37.

Gibbs, G. (2006) 'Why assessment is changing', in Bryan, C. and Clegg, K. (eds), Innovative Assessment in Higher Education, London, Routledge.

Glasgow School of Social Work (2007) MA with Honours in Social Work: Practice Learning Handbook 2007-8, Glasgow, Glasgow School of Social Work.

Heron, G. (2008) 'Using students written feedback on "race" issues to enhance selfregulated learning', British Journal of Social Work, 38(2), pp. 376-94.

Ivanic, R., Clark, R. and Rimmershaw, R. (2000) 'What am I supposed to make of this? The messages conveyed to students by tutors' written comments', in Lea, M. R. and Stierer, B. (eds), Student Writing in Higher Education: New Contexts, Buckingham, SHRE/Open University Press.

Nicol, D. (2008) Transforming Assessment and Feedback: Enhancing Integration and Empowerment in the First Year, Mansfield, Scottish Quality Assurance Agency for Higher Education.

Nicol, D. and Macfalane-Dick, D. (2006) 'Formative assessment and self-regulated learning: A model and seven principles of good feedback practice', Studies in Higher Education, 31(2), pp. 199-218.

O'Donovan, B., Price, M. and Rust, C. (2000) 'The student experience of criterionreferenced assessment (through the introduction of a common criteria assessment grid)', Innovations in Education and Teaching International, 37(1), pp. 74-85.

O'Donovan, B., Price, M. and Rust, C. (2008) 'Developing student understanding of assessment standards: A nested hierarchy of approaches', Teaching in Higher Education, 13(2), pp. 205-17.

Razack, N. and Badwall, H. (2006) 'Regional perspectives ... from North America', International Social Work, 49(5), pp. 661-6.

Risler, E. (1999) 'Student practice portfolios: Integrating diversity and learning in the field experience', Aretê, 23(1), pp. 89-96.

Sadler, D. R. (1989) 'Formative assessment and the design of instructional systems', Instructional Science, 18, pp. 119-44.

Shay, S. (2008) 'Beyond social constructivist perspectives on assessment: The centring of knowledge', Teaching in Higher Education, 13(5), pp. 595-605. 
Sidell, N. L. (2003) 'The course portfolio: A valuable teaching tool', Journal of Teaching in Social Work, 23(3/4), pp. 91-106.

Slater, P. (2007) 'The passing of the practice teaching award: History, legacy, prospects', Social Work Education, 26(8), pp. 749-62.

Taylor, I., Thomas, J. and Sage, H. (1999) 'Portfolios for learning and assessment: Laying the foundations for continuing professional development', Social Work Education, 18, pp. $147-60$.

The Quality Assurance Agency for Higher Education (2007) Enhancing Practice: Integrative Assessment: Managing Assessment Practices and Procedures, Guide No. 4, Mansfield, The Quality Assurance Agency for Higher Education.

Williams, B. (2001) 'The theoretical links between problem-based learning and selfdirected learning for continuing professional nursing education', Teaching in Higher Education, 6, pp. 85-98.

Williams, C. and Soydan, H. (2005) 'When and how does ethnicity matter? A crossnational study of social work responses to ethnicity in child protection cases', British Journal of Social Work, 35(6), pp. 901-20.

Yorke, M. (2003) 'Formative assessment in higher education: Moves towards theory and the enhancement of pedagogical practice', Higher Education, 45(4), pp. 477-501. 